LISBOA, Karen Macknow. Seguindo os passos não dados de Alexander von Humboldt e A. Bonpland no Brasil oitocentista. História, Ciências, Saúde Manguinhos, Rio de Janeiro, v.27, n.3, jul.-set. 2020, p.763-779.

\title{
Seguindo os passos não dados de Alexander von Humboldt e A. Bonpland no Brasil oitocentista
}

Following the paths not taken by Alexander von Humboldt and A. Bonpland in nineteenth-century Brazil

\section{Karen Macknow Lisboa ${ }^{i}$}

'Professora visitante do Programa de Pós-graduação em História Social/ Universidade de São Paulo. São Paulo - SP - Brasil

orcid.org/0000-0003-3914-3378

karenlisboa@me.com

Recebido em 17 maio 2019.

Aprovado em 18 nov. 2019.

Resumo

$\mathrm{O}$ artigo analisa a presença das ideias, da obra e dos personagens Alexander von Humboldt e Aimé Bonpland no Brasil oitocentista. Considerando a postura antiescravagista de Humboldt, investiga-se na primeira parte do texto o impacto de suas ideias entre alguns autores brasileiros antiescravagistas e abolicionistas. Na segunda parte, pesquisa-se a presença de Humboldt e Bonpland no maior e mais importante diário no Brasil, o Jornal do Commercio (RJ). Rastreando edições ao longo de mais de setenta anos, procurou-se analisar a diversidade das imagens que se construíram de ambos, com maior destaque a Humboldt, devido à sua importância como naturalista $\mathrm{e}$ intelectual versado em assuntos latinoamericanos.

Palavras-chave: Alexander von Humboldt (1769-1859); Aimé Bonpland (17731858); literatura antiescravagista; Jornal do Commercio; Brasil oitocentista.

\section{Abstract}

This article analyzes the presence of the ideas and work of Alexander von Humboldt and Aimé Bonpland in nineteenth-century Brazil. Given Humboldt's antislavery position, the first part of the text investigated the impact of his ideas on some Brazilian anti-slavery and abolitionist authors. In the second part, we study the presence of Humboldt and Bonpland in the largest, most important newspaper in Brazil, the Jornal do Commercio (RJ). Studying issues from a period of over seventy years, we sought to analyze the variety of images constructed of each, focusing more on Humboldt due to his importance as a naturalist and intellectual versed in Latin American issues.

Keywords: Alexander von Humboldt (17691859); Aimé Bonpland (1773-1858); antislavery literature; Jornal do Commercio; nineteenth-century Brazil. 
É uma história já conhecida: em 1800, Alexander von Humboldt e Aimé Bonpland foram impedidos de transpor a fronteira entre a colônia espanhola e a portuguesa (Humboldt, 1999, v.2, p.1100-1101; Lisboa, 2013). Se a ambos não foi facultado estudar nossas paragens tropicais, sua "ciência da viagem", no entanto, espalhou-se entre os viajantes e naturalistas que vieram ao Brasil, tornando-se importante referência do ponto de vista prático e teórico. Como estrelas-guias para posteriores missões "viajeiras" pela América Latina, sobretudo Humboldt indicou, motivou e apoiou a execução de muitas dessas missões $^{1}$ (Leite, 1997; Ette, 2009; Lisboa, 2013). Nesse sentido, é possível afirmar que a obra de Humboldt (e Bonpland) espraiou-se no Brasil por meio de outros autores que viajaram por nossas paragens e deixaram obras relevantes, tais como Johann von Spix e Carl von Martius, Moritz Rugendas, Wilhelm von Eschwege, príncipe Maximilian de Wied-Neuwied, Auguste de St. Hilaire, Charles Darwin, Henry Bates, Alfred Russel Wallace (Lisboa, 2013; Kury, 2014; Wulf, 2015).

Apesar do impacto da viagem e da obra de Humboldt e Bonpland na Europa e de uma, por assim dizer, recepção ${ }^{2}$ indireta por intermédio de outros autores no Brasil do século XIX, pouco se sabe de sua recepção direta. Considerando por exemplo as traduções feitas até o momento, apenas o livro de Humboldt, Ansichten der Natur (1986), ${ }^{3}$ foi vertido ao português, e publicado na década de 1950 (Humboldt, 1950).

O desconhecimento e a amplitude da questão - rastrear a presença de Humboldt/ Bonpland no meio brasileiro oitocentista - impõem, evidentemente, recortes. A presente investigação se balizará da seguinte forma: na primeira parte, verifico em obras de relevantes intelectuais brasileiros críticos à escravidão se há algum diálogo ou aproximação com o naturalista, considerando a posição antiescravagista de Humboldt, problematizada em inúmeras passagens de sua obra (1808-1811, 1814-1825, 1970 - esta publicada originalmente em Paris, entre 1814 e 1825) e, sobretudo, no ensaio político sobre Cuba (1826). Na segunda parte, investigo a presença de ambos no Jornal do Commercio, principal periódico e de maior continuidade no Império. Urge acrescentar que não só estaremos verificando aspectos da recepção da obra, ou seja, de sua produção intelectual, mas igualmente menções aos próprios personagens (aspectos biográficos, referências culturais, usos mercadológicos) e aos livros como produtos do mercado livreiro.

\section{"Não se pode deixar de citar a cada passo esta obra imortal": aproximações entre Humboldt e escritores antiescravagistas brasileiros}

Entre os políticos e intelectuais de destaque da primeira metade do século XIX, encontrase José Bonifácio de Andrada e Silva. Muito já se escreveu a seu respeito, e não é aqui o lugar de recontar sua fascinante trajetória de vida. Mas um episódio urge ser retomado: em diversos trabalhos biográficos, afirma-se que Bonifácio teria conhecido Alexander von Humboldt e dele se tornado amigo quando frequentou a Academia de Freiberg, na Saxônia. No entanto, segundo os dados biográficos de ambos, não necessariamente os dois chegaram a se conhecer na academia e menos ainda compartilhar os estudos. ${ }^{4}$ Pois Humboldt deixou a academia em final de fevereiro de 1792. Bonifácio teria chegado depois de agosto de 1792 e permanecido até $1793 .{ }^{5}$ Certamente há um diálogo entre os estudos mineralógicos de 
Humboldt e Bonifácio, pois se formaram na mesma instituição em períodos próximos, mas a amizade entre ambos não se evidencia.

Mario Barata (1963) considera que, para José Bonifácio, a geografia e a história lhe mereciam atenção. Ao extrair trechos ou sintetizar observações de Humboldt, ao que parece da obra Voyage aux régions équinoxiales... (1816 a 1831), o mineralogista brasileiro coletava informações sobre o extremo norte do Brasil, onde ele mesmo jamais estivera. ${ }^{6}$ Também pode se perscrutar as marcas de Humboldt em Bonifácio no campo da agricultura (Pádua, 2004). Humboldt foi um arguto observador da dilapidação ambiental causada pelo desflorestamento, a exemplo do que ocorria no lago de Valencia, na atual Venezuela. Essas observações reverberaram na obra de Bonifácio (Pádua, 2004).

Talvez Humboldt também tivesse tido algum impacto sobre o pensamento antiescravagista de Bonifácio. No entanto, no principal texto que aborda essa questão, publicado em 1825, Representação à Assembleia Geral Constituinte e Legislativa do Império do Brasil sobre a escravatura (Silva, 1988), não há referências ao filósofo viajante. Diferentemente, por exemplo, de João Severiano Maciel da Costa (1988), em cuja Memória, originalmente publicada em 1821, as visões de Humboldt, entre outros autores, sustentam alguns argumentos e oferecem informações. ${ }^{7}$ Por exemplo, Costa $(1988$, p.39) menciona as descrições elogiosas que Humboldt teceu sobre "a florescente agricultura e os incríveis trabalhos em minas feitos pelos indígenas" no México. O autor estava preocupado em demonstrar a capacidade laboriosa dos autóctones de modo geral, que poderiam ter sido empregados como trabalhadores, em vez da mão de obra africana escravizada. Costa (p.32) se refere a Humboldt, que categoricamente recusava a "opinião de alguns escritores, que declamam sobre a degeneração da nossa espécie na zona tórrida e a incapacidade dos indígenas para trabalhos penosos". ${ }^{8}$ Mais adiante, na parte em que analisa a lucratividade do trabalho agrícola com escravos, afirma em nota de rodapé: "Mr. de Humboldt prova mesmo que o trabalho por escravos é menos lucrativo no seu Ensaio político sobre o México. Não se pode deixar de citar a cada passo esta obra imortal, que é uma enciclopédia dos mais profundos e variados conhecimentos e que espanta a quem sabe quanto custa adquirir ideias em um só ramo de ciências" (p.58, nota 35). ${ }^{9}$

Outro autor crítico à escravidão ainda no mesmo período é Frederico Leopoldo Cesar Burlamaqui. Em sua Memória, publicada em 1837, ele se utiliza do relato de viagem de Humboldt ${ }^{10}$ para criticar o tráfico negreiro transatlântico e a continuação da introdução de africanos no Brasil, atividades ilegais: ${ }^{11}$

Se o despotismo e o arbítrio valessem alguma vez a favor da humanidade seria em tal ocasião sem contradição porque, na verdade, como diz o ilustre Humboldt, nada pode, senão o arbítrio, extinguir as especulações de um vil interesse em luta com os deveres da humanidade, a honra nacional e os direitos da pátria. Pela honra e brio nacional, pela reputação do nosso governo, todos os meios deveriam ser postos em prática para extirpar um semelhante comércio (Burlamaqui, 1988, p.114).

As observações que Humboldt teceu sobre a laboriosidade dos habitantes das Canárias serve, aos olhos de Burlamaqui (1988, p.189-190), também para atestar a capacidade de trabalho dos açorianos, considerados por ele excelentes imigrantes para o Brasil. Entre os 
importantes abolicionistas e reformadores da segunda metade do século XIX, tais como André Rebouças ${ }^{12}$ e Joaquim Nabuco, as referências a Humboldt são poucas. Em Propaganda abolicionista e democrática (1988), de Rebouças, Humboldt é mencionado uma vez, muito brevemente. No capítulo 21, Rebouças advoga por uma reforma agrária e chama a atenção para o fato de que a forma de cultivar o café estaria devastando a natureza, citando o naturalista: "A Europa está calva, disse Humboldt. Se continuarmos do mesmo modo teremos em breve despejado o Brasil dos riquíssimos cabelos, das preciosas florestas, que a natureza lhe deu" (p.141).

Em uma das mais importantes obras antiescravagistas, $O$ abolicionismo, escrita por Joaquim Nabuco em 1883, o viajante prussiano é mencionado apenas uma vez, na companhia de José Bonifácio, Agassiz e Darwin. Como "homens de ciência" que visitaram países americanos, insurgiram-se contra a escravidão reinante e expressaram sentimentos de repulsa (Nabuco, 2003, p.197). No livro memorialístico de Nabuco, Minha formação, a figura de Humboldt aparece duas vezes, de maneira curiosa. Quando defende com unhas e dentes sua outra bandeira - a monarquia constitucional -, Joaquim Nabuco (1998, p.29) sugere rebatizar o opus magnum de Humboldt, o que certamente teria causado muito desgosto ao republicano convicto: "Desistir da ideia monárquica não é tão fácil como parece. Mesmo o sistema planetário é monárquico, diz Schopenhauer. O universo é a Monarquia por excelência. Em vez de Cosmos, Humboldt podia ter dado ao seu livro o título de Monarquia. A ideia central de infinito, isto é, Deus, não podia deixar de ser em toda a esfera da inteligência e da atividade humana o verdadeiro ideal".

A outra referência à figura do naturalista se concretiza na descrição elogiosa que Nabuco faz a um colega e amigo alemão, o barão de Tautphoeus. ${ }^{13}$ Por sua erudição, inteligência e gosto pela natureza tropical, nele Nabuco (1998, p.67) projetou a figura de Humboldt, emprestando uma passagem da famosa conversa de Goethe com o secretário Eckermann sobre o viajante: "Que homem ele é! Há tanto tempo, tanto, que o conheço, e ele é sempre novo para mim. Pode-se dizer que não tem igual, nem em ciência, nem em experiência".

É evidente que a seleção dos autores acima não cobre o conjunto de escritores antiescravagistas e/ou abolicionistas no Brasil oitocentista. Aqui procuramos tecer possíveis aproximações e apropriações de alguns poucos escritores com o pensamento de Humboldt. Sem nos alongar a possíveis conclusões, podemos afirmar que a presença de Humboldt/ Bonpland é razoavelmente tímida e bastante variada. Essa variação também se reproduziu ao verificarmos essa presença no Jornal do Commercio, como veremos a seguir.

\section{"Foi o sol que nos mostrou a toda a luz aos olhos do Velho Mundo": Humboldt e Bonpland no Jornal do Commercio}

O Jornal do Commercio, publicado de $1^{\circ}$ de outubro de 1827 a 29 de abril de 2016, era o segundo periódico diário mais antigo, de tiragem regular, do Brasil, e um dos mais antigos de toda a América Latina. Foi fundado pelo tipógrafo parisiense Pierre René François Plancher de La Noé, que se exilou de seu país por sua convicção bonapartista, instalandose na Corte brasileira em 1824. La Noé trouxe uma oficina tipográfica completa. O Jornal do Commercio teve ao longo do século XIX vários proprietários, o que não prejudicou sua 
regularidade e importância. Se nos primeiros anos voltou-se mais para assuntos econômicos e comerciais, a partir da década de 1830, demonstra simpatia ao posicionamento político dos conservadores. Com a ocupação do trono por Pedro II na década de 1840, o jornal vem a ser porta-voz dos interesses do governo imperial, período em que se torna o jornal de maior circulação no país, exercendo influência junto à opinião pública, semelhante à influência do The Times na Europa, que lhe serviu também de modelo. Contou com a colaboração de figuras como Joaquim Manuel de Macedo, Joaquim Nabuco, Justiniano José da Rocha e Gonçalves Dias, como redatores dos discursos parlamentares, e, a partir de 1859, veiculando os registros das sessões da Câmara e do Senado (Molina, 2015).

$\mathrm{Na}$ presente investigação, examinaram-se edições ao longo de 82 anos de Jornal do Commercio. De 1827 a 1899, revelaram-se 711 ocorrências com a palavra-chave "Humboldt", sendo que a década de 1870 é a mais profícua, com 278 registros, superando a década anterior, com 131 registros. ${ }^{14} \mathrm{~A}$ análise se divide em dois segmentos. O primeiro contempla o período de 1827 a 1859 (ano da morte de Humboldt), e o segundo, de 1860 a 1899 . No primeiro segmento, registram-se 47 ocorrências, evidenciando que, após 1860, o número de ocorrências aumenta vertiginosamente.

Vejamos em mais detalhes a primeira etapa. Das 47 ocorrências, por volta de dez são anúncios da venda de exemplares dos livros de viagem. A livraria Souza Laemmert e Comp. anuncia em 1829 (Jornal do Commercio, 1827-1899 [n.382, 1829]) ${ }^{15}$ Tableaux de la nature ou considerations sur les deserts, sur la physionomie de vegetaux, sur les caracteres de l'Orenoque (2 v.). Seguem-se variados anúncios do Essai politique sur le royaume de la Nouvelle Espagne, avec atlas physique et geographique. Na loja de Evaristo Ferreira da Veiga, vende-se a Viagem às regiões equinociais do Novo Continente em 1799 até 1804 (5 v.), com título em português, embora a tradução não existisse. Na casa de J. Villeneuve e Comp., ou seja, na livraria dos próprios proprietários do jornal, ${ }^{16}$ era possível adquirir exemplares do Voyage pittoresque dans les deux Ameriques (Jornal do Commercio, 1827-1899 [n.28, 1837]). Também é anunciado (Jornal do Commercio, 1827-1899 [n.268, 1839]) um "Leilão dos trastes do Sr. Conde Ney", primeiro secretário da legação francesa que volta para a Europa. Ao lado dos objetos, livros e mapas, são vendidas "obras dos melhores autores, como Cuvier, Humboldt, Vie de Lord Byron". Em 1844 (Jornal do Commercio, 1827-1899 [n.43, 1844]), publica-se a lista de "livros em Francês para estudar medicina", e entre eles consta Humboldt, Quadros da natureza. Igualmente nesse caso, o título está em português, embora ainda não houvesse tradução da obra. Em 1847 (Jornal do Commercio, 1827-1899 [n.346, 1847]), aparece o primeiro anúncio "Humboldt: Cosmos, essai d'une déscription physique du monde l.1. Chez Mongie, 87, Rua d'Ouvidor". Em 1849 (Jornal do Commercio, 1827-1899 [n.89, 1849]), o segundo volume do Cosmos é divulgado. Até o final de 1859, Cosmos é anunciado somente mais uma vez, ao lado de Tableaux de la nature, e, em 1852, promove-se um leilão variado, incluindo "Grande obra de Humboldt e Bonpland com vinte mapas".

Subtraindo-se as ocorrências relativas aos anúncios de publicações, apurou-se que Humboldt (e pouca vezes Bonpland) é mencionado em várias matérias de assuntos científicos que cobrem as áreas de botânica, zoologia, antropologia, arqueologia, geografia, mineralogia e astronomia. Contudo, chama atenção não haver nenhuma contribuição específica no estilo de resenha ou matéria sobre Humboldt/Bonpland e/ou suas obras. 
Entre esse leque temático, em 1839 (Jornal do Commercio, 1827-1899 [n.61, 1839]), é publicado artigo do Instituto Histórico e Geográfico Brasileiro (IHGB) cujo tema aparecerá ao longo do século: a questão das fronteiras do Brasil na região Norte, no caso acerca da restituição da Guiana Francesa até o rio Oiapoque. Em 1843, há mais um artigo a respeito dos limites entre a Guiana Britânica e o Brasil em que Humboldt afirma que uma certa região seria brasileira (Jornal do Commercio, 1827-1899 [n.134, 1843]). Outro assunto recorrente é a questão da possibilidade da construção de uma comunicação oceânica pelos istmos da Nicarágua e do Panamá. Humboldt é considerado um expert por ter apontado em quais localidades geográficas isso seria possível: "a união dos dois oceanos com preferência a qualquer dos pontos do continente americano designados por Humboldt" (Jornal do Commercio, 1827-1899 [n.98, 1841; n.104, 1855]). De resto, há referências variadas a Humboldt (e Bonpland) em artigos ou matérias de cunho científico: sobre as aves guácharos (Jornal do Commercio, 1827-1899 [n.110, 1839]), o costume indígena de comer terra (Jornal do Commercio, 1827-1899 [n.318, 1839]), a altura em que o condor pode voar (Jornal do Commercio, 1827-1899 [n.69, 1840]), a descoberta ou exploração de minas de ouro, de diamantes etc. (Jornal do Commercio, 1827-1899 [n.217, 1840; n.109, 1855]), os vulcões (Jornal do Commercio, 1827-1899 [n.109, 1855]), a profundidade dos oceanos (Jornal do Commercio, 1827-1899 [n.21, 1857]). O "sábio barão de Humboldt" também assume lugar de relevância no debate acerca das descobertas arqueológicas na América e a importância delas para sublinhar a existência de uma antiguidade americana comparável com a do Antigo Egito e da Grécia (Jornal do Commercio, 1827-1899 [n.5, 1845]).

Em 1856 (Jornal do Commercio, 1827-1899 [n.63. 1856]), Humboldt, considerado um "nestor dos sábios da Europa, e sem dúvida a autoridade mais irrecusável nas coisas da América", teceu elogios à recém-lançada História geral do Brasil, de Francisco Adolfo Varnhagen, que estava sendo anunciada. Essas seriam as palavras do naturalista sobre a obra: "Laboriosas investigações nos arquivos públicos, oferece a rara vantagem de ser inspirada pela impressão individual da fisionomia do país e compreende a grandeza dos destinos que se devem abrir ante aquele vasto império debaixo da influência de suas instituições sábias e liberais". ${ }^{17}$

A importância desse elogio se reitera com a publicação, em 30 de março de 1857 (Jornal do Commercio, 1827-1899 [n.87, 1857]), na seção "Literatura", na primeira página, com o título: "Da inspiração que oferece a natureza do Novo Mundo e seus poetas e particularmente o Brasil. Opinião a respeito de nosso país relativamente à questão desenvolvida pelos Srs. Alexandre de Humboldt, Santiago Nunes Ribeiro, Magalhães, Visconde de S. Leopoldo, Ferdinand Denis, Daniel Gaver e Philippe Boucher, D'Arcet, Valera etc.".

O autor Souza Silva ${ }^{18}$ discute no artigo $^{19}$ se o Brasil podia inspirar a imaginação de seus poetas. Esse assunto era pauta entre literatos estrangeiros de reconhecida importância e que "realmente simpatizam com a nossa pátria e por nações que se interessam pelas nossas coisas". Ele menciona Pedro Álvares Cabral e Pero Vaz de Caminha, tidos como referência dessas descrições favoráveis, seguidos imediatamente por Humboldt, o "ilustre sábio do nosso século, que averiguou com a profundidade de seus conhecimentos a força do reflexo do mundo sobre a imaginação do homem".

Humboldt, em suas "eruditas pesquisas sobre o sentimento da natureza", deixa ver "toda a importância dos países americanos, quando vieram pelo descobrimento a concorrer com 
o contingente de suas magníficas imagens". Souza Silva cita longas passagens de Cosmos, sublinhando o pioneirismo do naturalista: "Pela primeira vez ... o mundo dos trópicos apresentou aos Europeus a magnificência de suas planícies fecundas, todas as variedades da vida orgânica". Discorre ainda acerca das descrições de Humboldt a respeito da vontade e do desejo de descobrir novos lugares motivados pelo profundo "sentimento da natureza". Era isso que animava os viajantes, entre eles o grande descobridor Colombo.

$\mathrm{Na}$ ausência de um artigo mais específico sobre as obras da dupla naturalista, e em particular sobre o best-seller de Humboldt na Europa, ${ }^{20}$ a contribuição de Souza Silva acerca de Cosmos não deixa de ser relevante justamente por abordar uma questão recorrente nas décadas seguintes: a simpatia de Humboldt pela natureza dos trópicos americanos e o impacto de suas imagens positivas no Velho e no Novo Mundo. E nesse âmbito, a história da conquista e a da colonização europeia na América são revalorizadas em ambos os imaginários. ${ }^{21} \mathrm{O}$ elogio de Humboldt a Francisco Varnhagen se redimensiona nas relações culturais entre a Europa e o Brasil, notadamente marcadas pelo "sentimento de inferioridade" das elites brasileiras em relação à Europa culta.

Também há nesse período breves notícias biográficas. Em 1839 (Jornal do Commercio, 1827-1899 [n.98, 1839]), em matéria sobre a invenção das gravuras fotossensíveis de Daguerre sob o título "Revolução nas artes do desenho", Humboldt, Arago, Biot e outros teriam ficado "suspensos e enfeitiçados" com a invenção de Daguerre. Em 1842 (Jornal do Commercio, 1827-1899 [n.42, 1842]), noticia-se que Humboldt acompanhou o rei da Prússia em sua viagem à Inglaterra. Em 3 de maio de 1848 (Jornal do Commercio, 1827-1899 [n.122, 1848]), é a vez de Bonpland ser mencionado: em "Notícias diversas", lê-se que o presidente Luiz Napoleão nomeou oficial da ordem da Legião de Honra o "sábio botanista Bonpland", companheiro do "célebre" Humboldt. E em 1856 (Jornal do Commercio, 1827-1899 [n.69, 1856]), o leitor no Brasil é informado de que a municipalidade de Berlim mandou entregar por uma deputação ao "decano dos sábios europeus Alexander von Humboldt uma patente de burguês da cidade impressa em cetim branco". São pequenas notícias que, por isso mesmo, geram estranhamento diante do fato de que a morte de Humboldt, em 6 de maio de 1859, não foi de imediato assunto nas páginas do jornal. A de Bonpland, em 11 de maio de 1858, foi noticiada seis semanas após o acontecido: o "célebre naturalista", "sequestrado" e forçado a ser paraguaio pela mão do ditador Francia, fora proibido de deixar o país. Após a morte de Francia, esclarece a notícia, Bonpland poderia deixá-lo. Estava, porém, velho demais, e nessa "vasta prisão" permaneceu, perdendo os seus mais "belos" anos de vida ${ }^{22}$ (Jornal do Commercio, 1827-1899 [n.181, 1858]). Na edição seguinte, retoma-se o assunto com mais precisão. Após reiterar as honras ao falecido por sua relevante contribuição científica, sublinha-se que, depois da morte do ditador, ele vivia entre a República de Corrientes (Argentina) e o Brasil, pelo qual nunca deixou de nutrir "a maior predileção e a mais viva simpatia". Seus estudos naturalistas, por versarem sobre uma região vizinha, seriam portanto de farto interesse aos brasileiros. Por fim, lastima-se que ele não tivesse fixado residência no Império, o que teria sido um ganho para o país (Jornal do Commercio, 1827-1899 [n.182, 1858]).

A segunda etapa da análise cobre de 1860 a 1899. A década de 1860 aponta 131 ocorrências, ou seja, quatro vezes mais do que na anterior (21 ocorrências). Engana-se, 
porém, o pesquisador ao achar que Humboldt obteve mais importância. Dessas numerosas ocorrências, mais de cem são anúncio do vapor Humboldt, navio inglês de carga e de passageiros que realizou viagens transatlânticas por mais de quatro décadas. ${ }^{23}$ Se subtrairmos os anúncios dessa embarcação, verificamos que, por décadas, a ocorrência de trinta a quarenta vezes do nome Humboldt permanece estável ao longo de 1860 até 1899.

Oito meses após a morte de Humboldt, em 12 de fevereiro de 1860, é publicado o necrológio em sua homenagem, discursado originalmente no IHGB por Joaquim Manoel de Macedo $^{24}$ (Jornal do Commercio, 1827-1899 [n.43, 1860]). O mote da homenagem é inspirado em uma comparação entre "Dois gigantes que tinham que realizar empresas imensas. Dois conquistadores ... que deviam marchar por caminhos opostos, e imortalizar-se por vitórias admiráveis, mas de natureza diversa". Macedo compara a trajetória de Humboldt à de Napoleão Bonaparte, que nasceu um mês antes do barão prussiano, em 1769. É bastante provável que Macedo se aproprie aqui de um cotejo que o filósofo norte-americano Ralph Waldo Emerson já lançara na década de 1840, ao denominar Humboldt "o Napoleão dos viajantes e das enciclopédias científicas" (Myerson, 1997, p.278).

Macedo compara as conquistas de Napoleão às conquistas científicas de Humboldt. “Em 1799, Napoleão atravessa o Mediterrâneo e deixa o Egito para chegar a Paris e subir ao Consulado; no mesmo ano Humboldt ... desembarca primeiro nas Canárias, escapando, como o general francês, aos navios da Inglaterra" (Jornal do Commercio, 1827-1899 [n.43, 1860]). Napoleão, o novo César, conquista províncias para a França e um reino para si, enquanto Humboldt conquistaria para a geografia, a história e as ciências naturais o Novo Mundo, enaltecendo sua beleza e a relevância da descoberta de Cristóvão Colombo. Nada escaparia ao seu olhar. "Ele apresenta à Europa o quadro da América sob o ponto de vista da topografia, da física, da geologia, da botânica, da astronomia, da zoologia e do estado moral e político de seus habitantes" (Jornal do Commercio, 1827-1899 [n.43, 1860]). Macedo descreve rapidamente o itinerário - os lugares e os povos indígenas que visitou. As escaladas que fez dos vulcões - Antisana, Cotopaxi e, finalmente, Chimborazo. Compara-o a uma "águia da ciência", que desprendeu o voo e atingiu o pico mais elevado do mundo em 23 de julho de 1802. Depois de escalar a maior das montanhas, dirigiu-se ao maior dos rios". Enquanto Bonaparte já estava morto, em 1829, aos 60 anos Humboldt faz a expedição à Rússia. Era "o sábio" que sobreviveu "ao guerreiro", afirma o autor, considerando também desnecessário enumerar suas obras, tão conhecidas. E quem não as conhecia, nunca teria estudado a história da América e do Brasil (Jornal do Commercio, 1827-1899 [n.43, 1860]).

Finalmente, Humboldt também é comparado a Colombo, vindo a ser o "segundo" descobridor da América. Ao patentear a magnificência de sua natureza e ter estudado seus habitantes, a América e o Brasil muito lhe deviam: "Foi o sol que nos mostrou a toda a luz aos olhos do Velho Mundo" (Jornal do Commercio, 1827-1899 [n.43, 1860]). Apesar dessas palavras elogiosas, resta a dúvida se Macedo conhecia de fato mais detalhadamente a obra de Humboldt.

É possível afirmar que, além desse necrológio, o Jornal do Commercio não publicou outra matéria ou artigo que tratasse especificamente de Humboldt e/ou Bonpland. De 1860 a 1899, contam-se 25 anúncios de obras de Humboldt, sendo que dez são de vendas de exemplares de Cosmos. Além disso, para quem fosse muito afeito à figura de Humboldt, poderia adquirir 
um busto dele, conforme propaganda da E.E.H. Laemmert (Jornal do Commercio, 1827-1899 [n.180, 1860]). O nome do naturalista também foi instrumentalizado em utensílios mais práticos, como as "penas de Humboldt": "as afamadas penas dedicadas ao falecido Humboldt são conhecidas pela sua flexibilidade e resistência" (Jornal do Commercio, 1827-1899 [n.246, 1871; n.241, 1872]). E conforme anúncio de outro produto, Humboldt também serviu, acompanhado por naturalistas como Martius, de testemunha para certificar as virtudes milagrosas da planta Eryroxylon Coca (na verdade, Erythroxylum coca). Essa "famosa planta do Peru" era o ingrediente do "Vinho de coca do dr. Gibson" destinado ao tratamento de moléstias do estômago, respiratórias, anemia e chlorosis (Jornal do Commercio, 1827-1899 [n.185, 244, 1873; n.154, 1874; n.26, 28, 1875]).

Tal qual nas décadas anteriores, o naturalista franco-prussiano é citado em vários momentos como referência científica e homem "sábio", "ilustre". Em "Altos e baixos" (Jornal do Commercio, 7 jan. 1872 [Folhetim]) talvez se possa ler a melhor definição para a figura humboldtiana veiculada na imprensa: "Não conheço nada mais esmagador que um sábio alemão; e se o sábio é barão, ainda o sábio é maior. Lembrem-se de Humboldt".

Como referência científica, foram encontrados entre 1860 e 1899, grosso modo, 82 textos em que Humboldt é citado como referência geral ou como especialista em determinado assunto. ${ }^{25} \mathrm{Na}$ grande diversidade desses textos (notícias, matérias, artigos) - que não tratarei na íntegra por razões de espaço - evidenciam-se as contribuições a respeito de fronteiras políticas na região amazonense (Jornal do Commercio, 1827-1899 [n.357, 1890; n.218, 1891; n.152, 1898; n.200, 1898]), bem como no campo da geografia econômica. Por exemplo, com a notícia em 13 de abril de 1867 (Jornal do Commercio, 1827-1899 [n.103, 1867]) do ato do governo imperial de abrir o rio Amazonas. Com isso se realizaria a "profecia de Humboldt" segundo a qual essa abertura animaria a atividade comercial e industrial, repercutindo na Europa e nos EUA. Ou sobre a extensão do Amazonas (Jornal do Commercio, 1827-1899 [n.81, 1868]), a respeito da junção dos rios no Amazonas para fins comerciais e de navegação (Jornal do Commercio, 1827-1899 [n.112, 1870]), ou acerca da "profecia" humboldtiana da comunicação fluvial no Alto Amazonas (Jornal do Commercio, 1827-1899 [n.112, 1877]). Em 16 de março de 1883 (Jornal do Commercio, 1827-1899 [n.75, 1883]), um dos membros da comissão de estudos da ferrovia MadeiraMamoré descreve a viagem no rio Amazonas, no Pará, de onde zarparam à meia-noite. Ao clarear o dia, "contemplávamos extasiados as margens do rio colosso, que Humboldt denominou 'paraíso das gerações futuras'" (destaque no original). Em 1893 (Jornal do Commercio, 1827-1899 [n.256, 1893]), em extensa matéria sobre a bacia do Amazonas, abre-se um bom espaço para tratar da viagem da dupla naturalista. Mais uma vez, elogiase Humboldt, que "popularizou o conhecimento geográfico da América Meridional". Em outro artigo, demonstra-se que Humboldt foi um dos autores relevantes a enxergar as vantagens da América equinocial em relação a outras regiões equatoriais do Globo (Jornal do Commercio, 1827-1899 [n.231, 1897]). Em artigo assinado por um brasileiro no jornal Independance Belge, o caso da Amazônia serve para defender a habitabilidade do Congo. Trata-se de regiões tropicais que estão longe de ser um "deserto". Para sustentar o argumento, o autor cita "autoridades científicas" como Humboldt, Agassiz, La Condamine e Élisée Reclus (Jornal do Commercio, 1827-1899 [n.204, 1896]). 
Também é o naturalista Humboldt que abre os olhos para a degradação ambiental. Tal qual José Bonifácio, que no início do século dialoga com as críticas de Humboldt à maneira depredadora da agricultura, essa questão reaparece em 1874 (Jornal do Commercio, 18271899 [n.339, 1874]). Quando o assunto é hidrologia, no artigo intitulado "Devastação de florestas e sua influência sobre a abundância d'água" (Jornal do Commercio, 1827-1899 [n.87, 1878]), servem de base as observações de Humboldt do vale d'Araguá, na Venezuela, e do lago Tacarigua, onde ele verificou o decréscimo gradual do nível das águas. A causa dessa diminuição seria a devastação das matas, praticada durante um século na região. As palavras proféticas do naturalista apontam para as mazelas da civilização: "Os homens, em todos os climas, derrubando as árvores que cobrem as camadas e os flancos das montanhas, preparam de uma só vez duas grandes calamidades para as gerações futuras: a escassez de água e a falta de combustível".

Humboldt como profeta da civilização nos trópicos é, por fim, uma tópica que aparece em outros momentos, e não apenas quando se trata da Amazônia, como visto acima. Em 21 de outubro de 1878 (Jornal do Commercio, 1827-1899 [n.294, 1878]), noticia-se que Manoel Francisco Correia, na "conferência popular", no edifício das escolas públicas da freguesia da Glória, em presença de grande número de "senhoras e cavalheiros", bem como do imperador, proferiu palestra sobre a necessidade de educação moral, intelectual e física da "raça" brasileira para que o "dizer profético do mais ilustre dos verdadeiros sábios da nossa época, Humboldt", venha a se concretizar, pois "é esta raça digna de dominar numa região, como a nossa, onde a civilização do globo tem de concentrar-se um dia". Em 1887, em 2 de setembro, noticia-se que o mesmo orador, na Associação Promotora da Instrução, discursou acerca do "amor da pátria", recebendo aplausos efusivos. A Guerra do Paraguai teria evocado sentimentos de patriotismo, bem como a comemoração da Independência, que se aproximava. Nesse contexto, lembraria que o "Brasil é uma nação fadada pelo maior naturalista dos tempos modernos, pelo grande Humboldt, a ser o centro de uma nova pátria poderosa e rica" (Jornal do Commercio, 1827-1899 [n.245, 1887]). José de Alencar teria expressado projeção semelhante ao citar Humboldt a respeito de suas visões do futuro dos EUA (Jornal do Commercio, 1827-1899 [n.213, 1873]).

Quando, em 1880, festeja-se o terceiro centenário de Camões, Humboldt ganha espaço por ter analisado a obra camoniana do ponto de vista do "cosmógrafo", do "etnólogo" e do "pintor dos fenômenos marítimos". Graças a Humboldt, em Cosmos, nesse "admirável monumento à ciência", conforme o barão Homem de Mello, a "glória de Camões" cresceria a cada dia (Jornal do Commercio, 1827-1899 [n.161, 1880]). E caberiam ao prussiano as melhores análises, por ter compreendido de que modo em Camões o espetáculo da natureza se refletiria na imaginação humana (Jornal do Commercio, 1827-1899 [n.161, 1880]). Finalmente, Humboldt é homenageado em poema de Rozendo Moniz dedicado a Camões, recitado no Teatro Pedro II com presença do imperador (Jornal do Commercio, 1827-1899 [n.167, 1880]):

Entre povos irmãos, nesta homenagem póstuma, não posso distinguir as cores das bandeiras; se portuguesas são não sei, se brasileiras... só vejo humanidade acima das nações. Vejo o apreço de Humboldt ao grão pintor marítimo... 
A efeméride dos 400 anos do Descobrimento da América foi mais um ensejo para retomar as leituras humboldtianas sobre Colombo (Jornal do Commercio, 1827-1899 [n.207, 269, 1892]). Ainda nesse contexto, o Jornal do Commercio publica artigo traduzido do Economiste Français com o título "Consequências econômicas da descoberta do Novo Mundo". Discorre-se acerca da fraca presença da França na América no passado em virtude do protecionismo espanhol. Somente depois de 1815, com a restauração da paz, a emancipação das colônias espanholas, o incremento da navegação, a imigração e a publicação da grande viagem de Humboldt (1825) "foi que o Novo Mundo penetrou, de algum modo, nas preocupações da Europa e que foi possível entrever com alguma nitidez todas as consequências de sua descoberta" (Jornal do Commercio, 1827-1899 [n.328, 1892]).

Se Humboldt foi um dos protagonistas em veicular o conhecimento da América na Europa, conforme o artigo do Economiste Français, ele é visto pelos autores brasileiros como o inaugurador de uma história da civilização na contramão do eurocentrismo. Uma breve indicação para essa questão apareceu em 1845, como mencionado acima. Em artigo de 24 de dezembro de 1888 (Jornal do Commercio, 1827-1899 [n.358, 1888]) de Salvador de Mendonça, publicado originalmente no número 2 da Revista 13 de Maio, ela assume contornos mais evidentes: Humboldt, "com a vidência do gênio", foi considerado o primeiro a enfrentar a hipótese de que em tempos pré-históricos havia uma nação dominadora - a dos maias - da qual saíram as correntes migratórias que povoaram Ásia, Egito e Europa. A tese é considerada "bombástica" por sustentar que o berço da "raça humana" residia na América Central, não na Ásia, e sugerir uma inversão no "curso da história", e teria entre seus seguidores Brasseur de Bourbourg e Le Plongeon. ${ }^{26}$

Quem também inverte o curso da interpretação eurocêntrica da história é o general Couto de Magalhães. ${ }^{27}$ Em seu discurso proferido no IHGB, intitulado "O Centenário, aspecto americano da comemoração", o autor lança luz sobre as comemorações que estavam por vir em 1900 do Descobrimento do Brasil (Jornal do Commercio, 1827-1899 [n.248b, 1898]). O foco recai no período da conquista e o papel positivo que os indígenas ocuparam nesse processo. "A história, sempre escrita pelos europeus", critica Couto, tem uma imagem negativa dos indígenas, ao acusá-los de antropófagos, infiéis, glutões. Para desmentir essa versão, lembra superficialmente as descrições dos viajantes Humboldt, Martius, Darwin e Saint-Denis. ${ }^{28}$ E a história do Descobrimento seria prova disso: fazendo alianças com os portugueses, os indígenas foram "heróis", ajudando a expulsar os inimigos. Por fim, Couto sugere que os habitantes autóctones, que "erradamente" foram chamados de "índios", e seus descendentes de "mestiços", deveriam ser denominados "americanos". A eles é que se deve "em parte", segundo Couto, "a grandeza de nossas terras, a unidade de nossa pátria debaixo de um só governo". Que esse artigo tenha sido publicado no dia 7 de setembro, ao lado de uma matéria destinada à celebração dos 76 anos da Independência, não parece ser fortuito. No esforço dos discursos constitutivos da nação independente e recém-republicana, as posições "antieuropeias" de Humboldt foram apropriadas a favor de uma historiografia nacionalista e patriótica. 


\section{Considerações finais}

Entre os cinco autores antiescravagistas e abolicionistas ora investigados, evidenciou-se que Humboldt tem uma presença bastante variada, enquanto Bonpland não é mencionado. Aquele que mais teve proximidade biográfica com o naturalista prussiano - José Bonifácio de Andrada - não o menciona em seu projeto emancipacionista, embora conhecesse a obra humboldtiana. Anterior a esse famoso texto, que marcou o pensamento antiescravagista no Brasil (Costa, 1998, p.398), João Severiano Maciel da Costa demonstra em sua contundente crítica que não só conhecia o aspecto antiescravista de Humboldt como o reconhecia como uma "enciclopédia" do conhecimento. Em semelhante seara encontrase Burlamaqui, que publica sua extensa memória 16 anos depois. Humboldt fornece argumentos para criticar o tráfico negreiro africano, que, apesar de ser considerado ilegal no Brasil desde 1831, continuava a ser praticado. As abordagens de Rebouças e Nabuco, depois de passadas quatro décadas, são distintas. Longe do Humboldt antiescravista, em Rebouças surge o Humboldt "ambientalista" avant la lettre, na mesma senda percorrida por Bonifácio de Andrada, sem atestar, no entanto, que o abolicionista tivesse lido Humboldt a fundo. Nabuco parece ir além, com um uso, por assim dizer, superficial da figura do barão. Ela tanto vale como testemunha ocular dos males da escravidão quanto como referência para descrever um colega bávaro refugiado nos trópicos cariocas. $\mathrm{E}$ Nabuco cutuca o consagrado autor do best-seller do século desejando rebatizar Cosmos como Monarquia. Sugestão ousada, à qual Humboldt - republicano - certamente teria retrucado com muitas farpas.

Variadas também são as apreensões de Humboldt e Bonpland e de sua obra no Jornal do Commercio. Desde algumas indicações sobre a circulação dos livros por meio dos anúncios de venda até o uso mercadológico da marca "Humboldt": servem para um vapor transatlântico, para pena de tinteiro e como selo de qualidade de vinho da folha de coca.

Evidenciou-se que o Jornal do Commercio deixa entrever o Humboldt enciclopedista - e de vez em quando com Bonpland -, figurando como fonte inesgotável para inúmeras matérias de assuntos científicos. Também o Humboldt ambientalista avant la lettre ganha espaço na década de 1870, período em que uma geração de intelectuais críticos propõe reformas políticas, econômicas e sociais diante da crise que se anuncia. ${ }^{29}$ Mas chama atenção o fato de que nessa perspectiva crítica o Humboldt antiescravista inexiste nas páginas do periódico. Ao longo das oito décadas ora investigadas, persiste a imagem do barão prussiano como grande ilustrado, o redescobridor da América, o reinventor das narrativas de uma natureza edênica, o crítico literário que liga os versos camonianos à história da expansão marítima, o novo Colombo que enxerga uma vindoura civilização nos trópicos, o arqueólogo na contramão do eurocentrismo, o valorizador da população original americana. E nesse sentido, reiterase aqui a importância da obra humboldtiana ao contribuir para os debates científicos e filosóficos sobre a natureza e cultura das Américas (tropical/equinocial/temperada) que circulam desde os meados do século XVIII. Como concluem Gerbi (1996), Ette (2002, 2009), Lubrich (2009), para mencionar somente alguns autores, Humboldt não somente propôs uma inversão das imagens negativas e detratoras sobre a América, ainda que com ambiguidades, mas também recusava a hierarquização das diferentes "raças" humanas. 
O primeiro aspecto do pensamento de Humboldt encontra-se nas páginas do Jornal do Commercio, como vimos, com adaptações. Já a questão racial fica à deriva.

E Bonpland permanece a tiracolo do grande visionário, quando não empurrado para a periferia dos pampas. Bonpland não equivale a Humboldt, mas se tivesse imigrado para o Brasil, assim garante o Jornal, teria sido um ganho para a nação. E eis uma das grandes questões veiculadas pelo relevante periódico conservador: discurso patriótico e construção nacional, que se cristaliza a partir de 1850. Pela pena (talvez da marca "Humboldt") de alguns conhecidos autores, como os românticos Souza Silva e Macedo ou o etnólogo Couto de Magalhães, ou dos menos conhecidos, como Manoel Francisco Correia em "conferências populares", o Jornal do Commercio se apropria das questões mais arrojadas da leitura positiva de Humboldt sobre a América tropical. Aquilo que Ottmar Ette (2002, p.145-150) considera fazer parte de um projeto de modernidade alternativo, marcado pela transnacionalidade, multiculturalidade e pela concepção de um desenvolvimento global como processo multipolar, é virado de ponta-cabeça, sendo dele selecionados os argumentos para veicular ideias ufanistas e reiterar uma agenda politicamente conservadora e nacionalista.

É evidente que ainda há muito a ser pesquisado sobre a presença, a recepção e apropriação de Humboldt e/ou Bonpland e suas obras no Brasil oitocentista. Um passo seguinte seria verificar a mesma questão em outros periódicos, autores e instituições (científicas/ acadêmicas) com o objetivo de melhor matizar o impacto desses relevantes naturalistas, com o destaque da figura de Humboldt.

\section{AGRADECIMENTOS}

A autora agradece a Mathias Eichbaum e Marina Duarte Sanchez, que auxiliaram na pesquisa documental.

\section{NOTAS}

${ }^{1}$ Pode-se listar alguns nomes de cientistas que vieram para o Brasil motivados, indicados e apoiados por Humboldt. Friedrich Sellow, que explorou o país por mais de 17 anos, viajou com Ignaz von Olfers, importante interlocutor de Humboldt, pelas províncias de São Paulo e Minas Gerais. Wilhelm Christian Gotthelf Feldner explorou por 11 anos as regiões do sul do país. Karl Ferdinand Appun viajou pelo Amazonas, e o príncipe Adalbert da Prússia foi ao rio Xingu. A edição inglesa de seu relato de viagem é prefaciada por Humboldt. Hermann Burmeister, um naturalista já na época notoriamente conhecido, viajou ao Brasil por indicação de Humboldt. Da mesma forma, Robert Avé-Lallemant. Eschwege encontrou-se com Humboldt assim que retornou para a Europa. Seu livro Beiträge zur Gebirgskunde Brasiliens (1832) foi dedicado a Humboldt. O marquês de Marialva teria pedido diretamente a Humboldt a indicação de nomes ilustres para enviar ao Brasil. Humboldt sugeriu Joaquim Lebreton para chefiar a famosa missão artística francesa (Andrä, 1962; Beck, 1977-1978).

${ }^{2}$ Com as teorias de H.R. Jauss e W. Iser, o termo recepção implica a constatação de que há uma relação dialética entre a "ortodoxia" de um texto com seus sentidos que os autores (e editores) definem e a liberdade de interpretação dos leitores, que cambiam ao longo do tempo e das mudanças socioculturais.

${ }^{3}$ A primeira edição é de 1808 , a segunda de 1826 e a terceira de 1849 , versão revista e aumentada. Sobre o impacto desse livro entre naturalistas que viajaram ao Brasil, ver Lisboa (2013).

${ }^{4}$ Juliano Moreira afirma, em 1912, que Humboldt e Andrada estudaram por meses juntos em Freiberg (citado em Santos-Stubbe, Stubbe, 2014, p.9). Otávio Tarquínio de Sousa (1945, p.39) reitera que Andrada conheceu Humboldt em Freiberg, "de quem se tornou amigo". Andrä (1962) retoma igual afirmação e diz que havia uma correspondência entre ambos. Jorge Caldeira (2002, p.17) assevera que Bonifácio se matriculou na universidade em Freiburg e lá encontrou Wilhelm von Humboldt, que teria sido "um de seus colegas mais íntimos". Bonifácio teria também estudado com Alexander. A confusão entre Academia 
de Freiberg e (universidade de) Freiburg é muito frequente. Vale dizer que Wilhelm jamais estudou em Freiberg, nem em Freiburg. Eis uma série de equívocos biográficos e geográficos decorrentes de um certo mito que se foi criando em torno da ideia de Bonifácio ter tido uma relação com duas grandes cabeças da ilustração europeia.

${ }^{5}$ Os dados cronológicos de Humboldt encontram-se detalhadamente em Ingo Schwarz (2019). Segundo Leinz (1792), Andrada e o colega Emanuel Ferreira da Câmara encaminharam, em 20 de setembro de 1792, um requerimento ao Conselho de Minas da Saxônia, solicitando autorização para frequentar a Academia Montanística e visitar a mineração. Ambos haviam deixado Paris em 10 de agosto de 1792 . A autorização é concedida em 5 de outubro, embora não lhes fosse permitido conhecer as minas de cobalto e arsênico e as fábricas de tintas azuis, usadas para colorir porcelanas.

${ }^{6}$ No arquivo do IHGB, há um conjunto de anotações de Andrada, sobretudo dos volumes 7, 8, 9 e 10 de Relation historique du voyage.

${ }^{7}$ Ver p.21, nota 8, p.29, nota 23, e p.49, nota 34.

${ }^{8}$ Costa se coloca aqui ao lado de Humboldt para criticar as teses decadentistas sobre a natureza e a população autóctone na América tropical defendidas por Buffon, Raynal, De Pauw etc. Acerca dessa "disputa" e a importância de Humboldt, ver Gerbi (1996); Ette (2009, p.76-78); Lisboa (2013).

${ }^{9}$ Costa se refere ao Essai politique sur le royaume de la Nouvelle-Espagne (1808-1811).

${ }^{10} \mathrm{Na}$ ausência de uma lista bibliográfica, contam apenas em notas de rodapé (5 e 52) as seguintes indicações: Viagens às regiões equinociais. Vale lembrar que o autor traduz o título ao português. Como o texto de Burlamaqui data de 1837, ele deve ter se servido da Rélation historique (1814-1825) (Burlamaqui, 1988).

${ }^{11} \mathrm{O}$ reconhecimento da independência do Brasil por parte do governo britânico dependia de o Brasil cessar o tráfico transatlântico de escravos. Somente em 1831 foi aprovada uma lei que o proibia. No entanto, o tráfico persistiu ilegalmente até 1850, findando com a aprovação e aplicação da Lei Eusébio de Queirós. Os africanos introduzidos após 1831 não poderiam ser escravizados, mas também isso não foi respeitado. O número de africanos que aportaram no Brasil entre 1831 e 1850 foi em média um dos mais altos da história do Brasil (Rodrigues, 2000; Alencastro, 2000).

${ }^{12}$ Foram consultados Diário e notas autobiográficas (Rebouças, 1938) e Propaganda abolicionista e democrática (Rebouças, 1988).

${ }_{13}$ Tautphoes teria emigrado para o Brasil como exilado da Baviera e se estabelecido no Rio de Janeiro (Nabuco, 1998, p.64).

${ }^{14}$ 1827-1829: uma ocorrência; 1830-1839: 12 ocorrências; 1840-1849: 13 ocorrências;1850-1859: 21 ocorrências; 1860-1869: 131 ocorrências; 1870-1879: 278 ocorrências; 1880-1889: 167 ocorrências; 1890-1899: 88 ocorrências. Entre essas ocorrências algumas se referem ao irmão de Alexander, Wilhelm von Humboldt, e a um sobrinho de Alexander, médico que contribuiu para pesquisas sobre a vacina contra a febre amarela. Bonpland é mencionado nesse período (1827-1899) 11 vezes, quase sempre em companhia de Humboldt.

${ }^{15}$ De agora em diante, colocaremos o número da edição e ano do jornal entre colchetes.

${ }^{16}$ Em 1832, Junius Villeneuve e Reól Antoine de Mongenot adquiriram o jornal do fundador.

${ }^{17}$ A respeito dos comentários de Humboldt sobre a obra de Varnhagen e o papel dos estudos de Humboldt na historiografia do Descobrimento de Varnhagen, ver Kalwa (1991) e Cezar (2007).

${ }^{18}$ Joaquim Norberto de Souza Silva (1820-1891) foi historiador, filólogo, musicólogo, poeta, romancista. Ingressou no IHGB em 1841 e dele tornou-se presidente. Sua obra se caracteriza pela estética romântica e por forte nacionalismo.

${ }^{19}$ Conforme indicado em nota de rodapé, trata-se de uma reprodução do segundo capítulo do Primeiro livro de história da literatura brasileira, de Joaquim Norberto de Souza Silva, lida em uma das sessões do IHGB em 1855. O IHGB foi fundado em 1838 e tornou-se a principal instituição de produção científico-cultural alinhada aos interesses políticos do governo monarquista. Entre os inúmeros membros ativos, muitos deles com cargos políticos e funcionários públicos, o próprio imperador era uma presença assídua. O IHGB figurou como importante incubadeira de uma historiografia e de uma literatura romântica nacional, veiculada em parte pela Revista do IHGB (Guimarães, L., 1995; Guimarães, M., 1988).

${ }^{20}$ A publicação do primeiro volume de Cosmos (1845) na Alemanha foi um sucesso editorial, seguido pelos volumes posteriores. Traduzido para vários idiomas, Cosmos conquistou o grande público leitor europeu e nas Américas, vindo a tornar-se um "cânone" da sociedade letrada. Nos EUA, após a morte de Humboldt, ele virou "moda" (Ette, Lubrich, 2004, p.919). 
${ }^{21}$ Excelentes (e em parte inovadoras) análises e interpretações a respeito da dimensão e da complexidade das visões humboldtianas sobre a América e sua importância no debate científico, filosófico e cultural (numa perspectiva transnacional), ver em Gerbi (1996), Ette (2002, 2009, entre outros) e Lubrich (2009). Especificamente sobre o Cosmos, opus magnum que Humboldt publicou em 1845, ver Ette, Lubrich (2004).

${ }^{22}$ A biografia de Bonpland depois de sua emigração para a América Latina é muito lacunar. Em 1820 teria viajado para a fronteira paraguaia a fim de realizar estudos científicos. Sua atividade foi vista como ameaçadora, e, no final de 1821, os soldados de Francia destruíram suas plantações de erva-mate e o levaram para o lado paraguaio, e lá o mantiveram aprisionado por nove anos, acusando-o de espionagem (Bonpland..., s.d.).

${ }^{23}$ Humboldt foi padrinho de batismo de diversos navios, que segundo suas palavras poderiam formar uma "potência naval". Essa prática se une à tradição de homenagear seu nome como toponímia em várias regiões do mundo (Wulf, 2015, p.343).

${ }^{24}$ Macedo (1820-1882), formado em medicina, rejeitou sua profissão, voltando-se para a carreira política, além de lecionar geografia e história no famoso Colégio Pedro II e ser preceptor das filhas da princesa Isabel. Como escritor de vasta obra, destacou-se com o romance A moreninha, best-seller da literatura romântica brasileira, que até hoje tem relevância na nossa cultura (Candido, 2006, p.453-461).

${ }^{25}$ Em uma matéria apenas Bonpland é citado como especialista na cultura da erva-mate (Jornal do Commercio, 1827-1899 [n.185, 1873]).

${ }^{26}$ Infelizmente o autor não indica com precisão em qual obra ou texto de Humboldt ele se baseia. A tese é bastante radical, e a princípio Humboldt recusa teorias que explicariam o surgimento da humanidade a partir de uma única origem. Além disso, ele estava muito atento aos diversos debates que procuravam explicar de modo geral esses assuntos, que inspiravam muito cuidado (Humboldt, 2009, p.20). Ele defendia a ideia de uma humanidade única, refutando porém o conceito de um único "berço civilizatório" e sugerindo assim um modelo de cultura policêntrico (Lubrich, 2009, p.172).

27 José Vieira Couto de Magalhães (1837-1898), formado em direito, foi um naturalista que percorreu muitas regiões do país e que se destacou nos estudos etnológicos. A publicação de O selvagem (1876), obra de encomenda a pedido do imperador destinada à Exposição Universal do Centenário da Independência de Filadélfia no mesmo ano, é fruto de suas observações de vários grupos indígenas e de seus estudos linguísticos. Couto de Magalhães ocupou cargos políticos, como a presidência das províncias de Goiás, Pará, Mato Grosso e São Paulo (Turin, 2012).

${ }^{28}$ Atribuir a C.F.P. von Martius uma visão positiva sobre os indígenas gera certo espanto. A maioria de suas considerações e análises - apesar de ambíguas - são em geral detratoras (Lisboa, 1997 entre outros). Igualmente não fica claro quem seria "Saint Denis". Couto de Magalhães talvez esteja se referindo ao historiador, viajante e crítico literário Ferdinand Denis, que viveu no Brasil entre 1816 e 1831.

${ }^{29}$ A conhecida "geração de 1870" surge no contexto da desestabilização política do Império após a Guerra do Paraguai e início da crise que anuncia o fim do escravismo. O pensamento dessa geração é antes reformador do que revolucionário (Alonso, 2002).

\section{REFERÊNCIAS}

ALENCASTRO, Luis Felipe de.

O trato dos viventes: formação do Brasil no Atlântico Sul. São Paulo: Companhia das Letras. 2000.

ALONSO, Angela.

Ideias em movimento: a geração 1870 na crise do Brasil Império. São Paulo: Paz e Terra. 2002.

ANDRÄ, Helmut.

Alexander von Humboldt e as suas relações com o Brasil. Revista de História, v.25, n.52, p.387403. 1962.

BARATA, Mario.

Viagens de estudos científicos de José Bonifácio e atividades na Intendência das Minas de Portugal. Revista do IHGB, v.260, p.238-257. 1963.
BECK, Hanno.

Novidades na pesquisa nos manuscritos deixados por von Eschwege. Staden-Jahrbuch, v.25-26, p.83-85. 1977-1978.

BONPLAND...

Bonpland, Aimé Jacques Alexandre (17731858). Global Plants. Disponível em: <https:// plants.jstor.org/stable/10.5555/al.ap.person. bm000000885 >. Acesso em: 11 ago. 2020. s.d.

BURLAMAQUI, Frederico Leopoldo Cesar. Memória analítica acerca do comércio dos escravos e dos males da escravidão doméstica. In: Salgado, Graça (Org.). Memórias sobre a escravidão. Brasília: Arquivo Nacional; Fundação Petrônio Portella. p.101-222. 1988. 
CALDEIRA, Jorge (Org.).

José Bonifácio de Andrade e Silva. São Paulo:

Editora 34. 2002.

CANDIDO, Antonio.

Formação da literatura brasileira: momentos decisivos, 1750-1880. Rio de Janeiro: Ouro sobre Azul. 2006.

CEZAR, Temístocles.

Varnhagen em movimento: breve antologia de uma existência. Topoi, v.8, n.15, p.159-207. 2007.

COSTA, Emília Viotti da.

Da senzala à Colônia. São Paulo: Editora da Unesp. 1998.

COSTA, João Severiano Maciel da.

Memória sobre a necessidade de abolir a introdução dos escravos africanos no Brasil... In: Salgado, Graça (Org.). Memórias sobre a escravidão. Brasília: Arquivo Nacional; Fundação Petrônio Portella. p.9-59. 1988.

ETTE, Ottmar.

Alexander von Humboldt und die Globalisierung.

Frankfurt a.M.: Insel. 2009.

ETTE, Ottmar.

Weltbewußtsein: Alexander von Humboldt und das unvollendete Projekt einer anderen der Moderne. Weilerswist: Velbrück Wissenschaft. 2002.

ETTE, Ottmar; LUBRICH, Oliver.

Nachwort. In: Humboldt, Alexander von. Kosmos: Entwurf einer physischen Weltbeschreibung. Frankfurt a.M.: Eichborn. 2004.

GERBI, Antonello.

O Novo Mundo: história de uma polêmica, 1750 1900. São Paulo: Companhia das Letras. 1996.

GUIMARÃES, Lucia Maria Paschoal.

Debaixo da imediata proteção de Sua Majestade Imperial: o Instituto Histórico e Geográfico Brasileiro (1838-1889). Revista do IHGB, n.388, p.459-613. 1995.

GUIMARÃES, Manuel Luiz Salgado. Nação e civilização nos trópicos: o IHGB e o projeto de uma história nacional. Estudos Históricos, v.1, p.5-27. 1988.

HUMBOLDT, Alexander von.

Ueber die Urvölker von Amerika und die

Denkmähler welche von ihnen übrig geblieben sind: Anthropologische und ethnographische Schriften. Textos editados por Oliver Lubrich. Erlangen: Wehrhahn. 2009.

HUMBOLDT, Alexander von.

Reise in die Äquinoktial-Gegenden des Neuen Kontinents. Frankfurt a.M.: Insel. 2v. 1999.
HUMBOLDT, Alexander von.

Ansichten der Natur mit wissenschaftlichen

Erläuterungen. Nordlingen: Franz Greno. 1986.

HUMBOLDT, Alexander von.

Relation historique du voyage aux régions

équinoxiales du Nouveau Continent fait en 1799,

1800, 1801, 1802, 1803, et 1804 par Al. de

Humboldt et A. Bonpland rédigé par Alexandre de

Humboldt. Stuttgart: Brockhaus. 3v. 1970.

HUMBOLDT, Alexander von.

Quadros da natureza. Rio de Janeiro: Jackson. 2v. 1950.

HUMBOLDT, Alexander von.

Essai politique sur l'ile de Cuba. Paris: Librairie de Gide Fils. 2v. 1826.

HUMBOLDT, Alexander von.

Essai politique sur le royaume de la Nouvelle-

Espagne. Paris: Chez F. Schoell. 2v. 1808-1811.

JORNAL DO COMMERCIO.

Jornal do Commercio. Edições de 1827 a 1899.

Hemeroteca da Biblioteca Nacional, Rio de

Janeiro. Disponível em: < http://bndigital.

bn.gov.br/hemeroteca-digital/>. Acesso em: 17 dez. 2017. 1827-1899.

KALWA, Erich.

Alexander von Humboldt, die

Entdeckungsgeschichte Brasiliens und die

brasilianische Geschichtschreibung des 19.

Jahrhunderts. Lusorama, v.16, p.65-95. 1991.

KURY, Lorelai.

As mil vozes da natureza. In: Kury, Lorelai (Org.). Representações da fauna no Brasil século XVI-XX. Rio de Janeiro: Andrea Jakobsson. p.160-199. 2014.

LEINZ, Viktor.

Documentos de ingresso de José Bonifácio de Andrada e Silva Ferreira da Câmara na Bergakademie de Freiberg, 1792. José Bonifácio - Obra completa. Disponível em: <http:// obrabonifacio.com.br/colecao/obra/1384/ digitalizacao>. Acesso em: 10 dez. 2017. 1792.

LEITE, Miriam L. Moreira.

Livros de viagem (1803-1900). Rio de Janeiro: Editora UFRJ. 1997.

LISBOA, Karen Macknow.

'Die Welt zwischen den Wendekreisen': Alexander von Humboldt und deutsche Brasilienreisende zu Beginn des 19. Jahrhunderts. In: Lubrich, Oliver; Knopp, Christine A. (Org.). Cumaná 1799: Alexander von Humboldt's travels between Europe and the Americas. Bielefeld: Aisthesis. p.309-338. 2013.

LISBOA, Karen Macknow.

A nova Atlântida de Spix e Martius: natureza e civilização na Viagem pelo Brasil (1817-1820). São Paulo: Hucitec; Fapesp. 1997. 
LUBRICH, Oliver.

Stufen, Keime, Licht: Alexander von Humboldt als Ethnograph und Anthrologe. In: HUMBOLDT, Alexander von. Ueber die Urvölker von Amerika und die Denkmähler welche von ihnen übrig geblieben sind: anthropologische und ethnographische Schriften. (Textos editados por Oliver Lubrich). Erlangen: Wehrhahn. p.167-190. 2009.

MOLINA, Matías M.

História dos jornais no Brasil: da Era Colonial à Regência, 1500-1840. São Paulo: Companhia das Letras. v.1. 2015.

MYERSON, Joel (Org.).

The selected letters of Ralph Waldo Emerson. New York: Columbia University Press. 1997.

NABUCO, Joaquim.

O abolicionismo. Brasília: Senado Federal. 2003.

NABUCO, Joaquim.

Minha formação. Brasília: Senado Federal.

Disponível em: < https://www2.senado.leg.br/bdsf/ handle/id/1019>. Acesso em: 17 ago. 2020. 1998.

PÁDUA, José Augusto.

Nature conservation and nature building in the thought of a Brazilian founding father: José Bonifácio (1763-1838). University of Oxford: Centre for Brazilian Studies. 2004.

REBOUÇAS, André.

Propaganda abolicionista e democrática. Recife: Fundação Joaquim Nabuco; Editora Massangana. 1988.

REBOUÇAS, André. Diário e notas autobiográficas. Rio de Janeiro: José Olympio. 1938.
RODRIGUES, Jaime.

O infame comércio: propostas e experiências no final do tráfico dos africanos para o Brasil (18001850). Campinas: Editora da Unicamp. 2000.

SANTOS-STUBBE, Chirly; STUBBE, Hannes. Kleines Lexikon der Afrobrasilianistik: eine Einführung mit Bibliografie. Göttingen: V\&R. 2014.

SCHWARZ, Ingo.

Alexander von Humboldt-Chronologie. In: Ette, Ottmar (Org.). Edition Humboldt digital. Berlin: Berlin-Brandenburgische Akademie der Wissenschaften. Disponível em: <https:// edition-humboldt.de/v5/H0002696>. Acesso em: 19 fev. 2019. 2019.

SILVA, José Bonifácio de Andrada e. Representação à Assembleia Geral Constituinte e Legislativa do Império do Brasil sobre a escravatura. In: Salgado, Graça (Org.). Memórias sobre a escravidão. Brasília: Arquivo Nacional Fundação Petrônio Portella. p.61-77. 1988.

SOUSA, Otávio Tarquínio de. José Bonifácio (1763-1838). São Paulo: José Olympio. 1945.

TURIN, Rodrigo

O 'selvagem' entre dois tempos: a escrita etnográfica de Couto de Magalhães. Varia Historia, v.28, n.1, p.781-803. 2012.

WULF, Andrea.

Alexander von Humboldt und die Erfindung der Natur. München: C. Bertelsmann. 2015. 